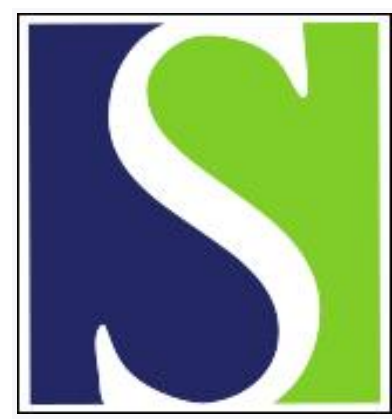

Scand J Work Environ Health 2008;34(6):451-462

https://doi.org/10.5271/sjweh.1291

Issue date: 00 Dec 2008

Behavior of aluminum in aluminum welders and manufacturers of aluminum sulfate-impact on biological monitoring

by Riihimäki V, Valkonen S, Engström B, Tossavainen A, Mutanen P, Aitio $\mathrm{A}$

Affiliation: Good Practices and Competence, Statistical Services, Finnish Institute of Occupational Health, Topeliuksenkatu 41 a A, FI-00250 Helsinki, Finland. [E-mail: vesa.riihimaki@ttl.fi

Refers to the following text of the Journal: 2000;26(2):118-130

Key terms: aluminum; aluminum sulfate; aluminum welder; aluminum welding fume; behavior; biological monitoring; manufacturer; toxicokinetics

This article in PubMed: www.ncbi.nlm.nih.gov/pubmed/19137207

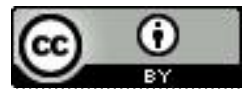




\title{
Behavior of aluminum in aluminum welders and manufacturers of aluminum sulfate-impact on biological monitoring
}

\author{
by Vesa Riihimäki, MD, ${ }^{1}$ Sinikka Valkonen, BSc (Eng), ${ }^{1}$ Bernt Engström, MSc, ${ }^{1}$ Antti \\ Tossavainen, PhD (Eng), ${ }^{1}$ Pertti Mutanen, MSc, ${ }^{1}$ Antero Aitio, MD ${ }^{1}$
}

\begin{abstract}
Riihimäki V, Valkonen S, Engström B, Tossavainen A, Mutanen P, Aitio A. Behavior of aluminum in aluminum welders and manufacturers of aluminum sulfate-impact on biological monitoring. Scand J Work Environ Health 2008;34(6):451-462.
\end{abstract}

Objectives The suitability of determining aluminum in serum or urine as a form of biological monitoring was critically assessed.

Methods Airborne and internal aluminum exposure was assessed for 12 aluminum welders in a shipyard and 5 manufacturers of aluminum sulfate. Particles were characterized with X-ray diffraction and scanning electron microscopy. Aluminum in air and biological samples was analyzed using electrothermal atomic absorption spectrometry. Basic toxicokinetic features were inferred from the data.

Results The mean 8-hour time-weighted average concentration of aluminum was 1.1 (range $0.008-6.1$ ) mg/m for the shipyard and 0.13 (range $0.02-0.5$ ) $\mathrm{mg} / \mathrm{m}^{3}$ for the aluminum sulfate plant. Welding fume contained aluminum oxide particles $<0.1 \mu \mathrm{m}$ in diameter and their agglomerates, whereas bauxite and aluminum sulfate particles ranged from 1 to $10 \mu \mathrm{m}$ in diameter. The shipyard welders' mean postshift serum and urinary concentrations of aluminum (S-Al and $\mathrm{U}-\mathrm{Al}$, respectively) were 0.22 and $3.4 \mu \mathrm{mol} / \mathrm{l}$, respectively, and the aluminum sulfate workers' corresponding values were 0.13 and $0.58 \mu \mathrm{mol} / \mathrm{l}$. Between two shifts, the welders' S-Al concentration decreased by about 50\% ( $\mathrm{P}<0.01)$, but their $\mathrm{U}-\mathrm{Al}$ concentration did not change $(\mathrm{P}=0.64)$. No corresponding temporal changes occurred among the aluminum sulfate workers. After aluminum welding at the shipyard had ceased, the median S-Al concentration decreased by about 50\% $(\mathrm{P}=0.007)$ within a year, but there was no change $(\mathrm{P}=0.75)$ in the corresponding U-Al concentration.

Conclusions About $1 \%$ of aluminum in welding fume appears to be rapidly absorbed from the lungs, whereas an undetermined fraction is retained and forms a lung burden. A higher fractional absorption of aluminum seems possible for aluminum sulfate workers without evidence of a lung burden. After rapid absorption, aluminum is slowly mobilized from the lung burden and dominates the S-Al and $\mathrm{U}-\mathrm{Al}$ concentrations of aluminum welders. For kinetic reasons, $\mathrm{S}-\mathrm{Al}$ or $\mathrm{U}-\mathrm{Al}$ concentrations cannot be used to estimate the accumulation of aluminum in the target organs of toxicity. However, using U-Al analysis to monitor aluminum welders' lung burden seems practical.

Key terms aluminum welding fume; toxicokinetics.

Aluminum metal is increasingly used for the manufacture of many kinds of vehicles and in the construction industry due to its light weight and resistance to corrosion. Processing the metal into products, ranging from leisure boats to railway cars and ships, commonly involves welding, which generates vapor condensation fumes. Similar fumes are generated during arc spraying with aluminum to coat steel structures. A common aluminum compound, different from the aforementioned aluminum fume, is aluminum sulfate $\left[\mathrm{Al}_{2}\left(\mathrm{SO}_{4}\right)_{3}\right]$, which is manufactured from bauxite ore and extensively used for water purification.
Aluminum is welded either with the metal inert gas (MIG) or tungsten inert gas (TIG) method. Especially the former produces copious welding fumes (1). In the high temperatures of the arc welding process, aluminum is vaporized and then quickly condensed, during which it primarily reacts with oxygen, into chains of ultrafine (diameter $<0.1 \mu \mathrm{m}$ ) singlet particles that tend to agglomerate. Aluminum metal and aluminum oxide $\left(\mathrm{Al}_{2} \mathrm{O}_{3}\right)$ are practically insoluble in water and are thus presumably poorly absorbed into living organisms. However, oxidized aluminum, contained in ultrafine particles, behaves differently, since some aluminum of

Correspondence to: Pertti Mutanen, Good Practices and Competence, Statistical Services, Finnish Institute of Occupational Health, Topeliuksenkatu 41 a A, FI-00250 Helsinki, Finland. [E-mail: pertti.mutanen@ttl.fi] 
the welding fume is rapidly taken up by the welder's lungs (2). Grinding and polishing accompany welding. Compared with welding fumes or dust, dusts emanating from grinding and polishing contain larger particles of metallic aluminum and its oxide; however, depending on the type of tools used, a variable fraction of the dust is expected to be respirable.

Aluminum sulfate is manufactured from bauxite ore-mainly $\mathrm{Al}(\mathrm{OH})_{3}$ —and sulfuric acid. The chemical process includes crushing bauxite, synthesizing the sulfate in a reactor, and drying, granulating and bagging the product. The bauxite ore aluminum is insoluble in water, whereas aluminum sulfate is water soluble.

Previously, several studies have investigated the environmental and internal exposure of workers to aluminum in welding (2-5) with the aim of evaluating the uptake and urinary excretion kinetics of the metal. With great detail, Matczak \& Gromiec (1) measured the concentrations of metals in the breathing zone of welders during the actual MIG or TIG welding of aluminum. Sjögren and his coworkers pioneered the development of biological monitoring practices based on the urinary aluminum excretion of aluminum welders. They demonstrated that the welder's urinary aluminum concentration, which could exceed the normal range by as much as 100-fold, depended partly on the level of current airborne exposure and partly on the duration of the exposure history (2). High concentrations of aluminum were found in the lungs of two aluminum welders who had died of pneumoconiosis induced by exposure to aluminum welding fumes (6).

Comparable studies concerned with aluminum sulfate production are lacking. Sjögren et al (3) found little indication of elevated aluminum levels in the blood and urine of aluminum sulfate production workers in spite of their many years of exposure in a relatively dusty environment.

The purpose of our present study was to examine the aluminum exposure and kinetics of aluminum in a group of shipyard workers engaged in welding and grinding when making ship hulls of aluminum and to compare these data with those of workers exposed to aluminum sulfate in aluminum sulfate production. By assessing changes in aluminum concentrations in biological fluids over a short time ( 2 workdays) and a long time (2 years), we strove to gain insight into the biological behavior of the aluminum species in the workers for the development of a meaningful biological monitoring method.

\section{Study population and methods}

\section{Study design}

This is an observational study among workers exposed to different aluminum compounds. We studied two groups of workers exposed to different aluminum compounds [(welders or fitters) and aluminum sulfate producers]. In addition, we manipulated the exposure scenario by varying the extent of the use of protection devices; we also had the opportunity to compare the accumulation of aluminum among workers with different histories of the use of protection devices. The study concentrated on short-term changes in the aluminum concentrations in body fluids, but we also had an opportunity to follow the long-term disappearance of aluminum among welders whose exposure ceased.

\section{Study population}

Workers from two companies, a shipyard and an aluminum sulfate plant, signed a written informed consent to take part in a study in which airborne exposure to aluminum was measured during their normal work, and blood and urine samples were collected during and after the exposure period for aluminum analysis. The study protocol was approved by the Ethics Committee of the Finnish Institute of Occupational Health.

In the shipyard, altogether 11 men and 1 woman, welders and fitters in equal number, were enrolled in the exposure study. Their mean age was 33.2 (range 27-46) years. In addition, six male fitters and one male welder [mean age 41.3 (range 35-48) years], also working with aluminum, and six welders and six fitters [11 men and 1 women; mean age 41.4 (range 30-60) years] working with mild steel only (local references) donated one blood sample and one urine sample. The welding was carried out with the MIG welding technique, using $\mathrm{Al} \mathrm{Mg}$ 4.5 Mn aluminum alloy and $\mathrm{Al} \mathrm{Mg} 5$ (diameter $1.2 \mathrm{~mm}$ ) welding wire, with argon as a shield gas.

In the aluminum sulfate plant, five male employees [mean age 46.2 (range 38-58) years] took part in the exposure study, and five of their male colleagues [mean age 53 (range 39-60) years] each donated one blood and one urine sample for the measurement of aluminum. In an adjoining fertilizer plant, each of six male workers [mean age 43.8 (range 30-55) years] provided one blood sample and one urine sample (local referents).

Occupational exposure history, use of medication, and dietary habits were queried to track sources of aluminum intake, and smoking status was noted. The shipyard employees had started working with aluminum 3-4 years before the initiation of the study, and they continued working up to 5 years (at which time the use of aluminum ceased at the shipyard) during the follow up. Both before and after the aluminum welding, the welders and fitters worked with mild steel over a mean period of about 12 years. Employees at the aluminum sulfate plant had a long work history, ranging from 12 to 31 (mean 22.9) years, and their careers typically involved shifts from one part of the process to another, including 
bagging the end product, which had previously been a dusty job. None of the participants were regular users of antacid medication; two of the welders or fitters and one aluminum sulfate worker reported taking neutralizing agents occasionally.

\section{Air sampling}

Particles in the personal air samples (two samples per shift) were collected on membrane filters (Millipore AAWP 037 or 025, Millipore Corp, Billerica, MA, USA) with a portable pump (Du Pont CFS Model S 2050, DuPont Applied Technology Division, Wilminton, DE, USA) over the effective worktime during two consecutive workdays. In the shipyard, the samples were collected from the inside of the welding helmet. Most of the welders and fitters either used a battery-driven pump that blew filtered air to the top of the helmet, or clean air from the compressed air system was used to flush the welding helmet. For the aluminum sulfate workers, the personal sampling filter was placed near the workers' breathing zone on the left shoulder. Separate air samples from typical worktasks were collected with high-volume samplers on polystyrene or polycarbonate filters for the characterization of the airborne particles with X-ray diffraction or scanning electron microscopy (SEM).

Contamination was avoided in all of the preanalytical steps. For the analysis of aluminum, the filters were dissolved in concentrated nitric acid. The aluminum concentration was determined with electrothermal atomic absorption spectrometry (ETAAS) employing Zeeman background correction. The detection limit for aluminum was $0.02 \mathrm{mg} / \mathrm{m}^{3}$. For the calculation of the 8 -hour time-weighted average (8-hour TWA) concentration it was assumed that, beyond the sampling time, there was no exposure. To characterize the airborne particles, $\mathrm{X}$-ray diffraction was used for a qualitative analysis of crystalline compounds, and the size, morphology, and element composition of the particles was further determined with SEM (Jeol 6400, Jeol Ltd, Tokyo, Japan) and an X-ray microanalyzer (Tracor Northern TN5500, Tracor Northern Inc, Middleton WI, USA).

\section{Biological samples}

Venous blood samples were taken at the end of the shift on study day I and in the morning of study day II, then again 1 year later before and immediately after the 4week summer vacation and, for the shipyard workers, 2 years after the start of the study. During study days I and II, the workers collected all of their excreted urine over the 48 hours in samples voided at 4- to 8-hour intervals. During the subsequent summer vacation, which started about 3 weeks later, they donated one morning urine sample per week over 4 weeks. One year later the workers submitted morning urine samples before and immediately after their 4-week summer vacation, and the shipyard workers submitted another sample again 2 years after the start of the study. It should be noted that the use of aluminum in the shipyard ended within a year from the start of the study, and, therefore, at the 1-year follow-up point, the welders and fitters had no longer been working with aluminum for periods that individually varied from 1 to 5 months. The workers in the two additional categories (fellow workers of those in the exposure groups, as well as local referents) each gave a blood and urine sample in the morning.

Meticulous care was taken to avoid external contamination during the sampling. Blood was collected into acid-washed glass tubes; serum was transferred using aluminum-free plastic pipettes within 1 hour into acid-washed plastic tubes. Urine samples were collected into acid-washed polyethylene bottles in a clean room separated from the work area, and the workers were instructed to take off their overalls and wash their hands and the tip of their penis before urinating. Sample preparation was performed under particulatefree conditions in a HEPA (high-efficiency particulate air) filtered laminar flow hood, and powder-free gloves were worn throughout. All of the laboratory equipment was acid-washed or acid-rinsed, and the reagents were of a aluminum-free high-purity grade.

Aluminum was determined in the serum and urine samples using ETAAS with Zeeman background correction (7). The aluminum concentrations in the urine samples were corrected to a relative density of 1.024 . The detection limits were $0.02 \mu \mathrm{mol} / \mathrm{l}$ for serum and $0.07 \mu \mathrm{mol} / \mathrm{l}$ for urine. The within-run imprecision $(\mathrm{CV})$ for serum and urine was $3 \%$ and $5 \%$, and the betweenday imprecision was $6 \%$ and $7.2 \%$, at a concentration level of $4.0 \mu \mathrm{mol} / 1$. The between-day imprecision for urinary aluminium was $15.7 \%$ at a concentration level of $0.24 \mu \mathrm{mol} / \mathrm{l}$. The quality procedures included the daily use of commercial reference materials and regular participation in external quality assessment schemes.

\section{Results}

\section{Particle characteristics}

Chemically, the particles generated from the welding and grinding of aluminum plates mainly consisted of aluminum oxide $\left(\mathrm{Al}_{2} \mathrm{O}_{3}\right)$ and aluminum metal. Iron and its oxide, quartz, calcium carbonate, and mineral dusts were also found and were contaminants from other sources. The electron microscopy revealed that the MIG welding fumes of aluminum collected on the filter were composed of chains of spherical singlet particles of 
$<0.1 \mu \mathrm{m}$ in diameter. The chains were agglomerated to larger units containing hundreds of singlet particles, a typical finding for the condensation fume of metal vapor. The element composition was consistent with aluminum oxide. Specimens sampled during grinding also contained irregularly shaped, 1-10 $\mu \mathrm{m}$ long particles of metallic and oxidized aluminum.

In the aluminum sulfate plant, the dust was mainly composed of bauxite $\left[\mathrm{Al}(\mathrm{OH})_{3}\right]$, other identified components being aluminum sulfate (hydrate), ferrous sulfate, ferric oxide, quartz, calcium carbonate, and clay minerals. In the scanning electron microscopy, particles of bauxite and aluminum sulfate with a diameter ranging from 1 to $10 \mu \mathrm{m}$ looked similar and could be distinguished only according to the element composition.

Table 1. Airborne 8-hour time-weighted average concentrations of total dust and aluminum measured in the respiratory zone of the shipyard welders and fitters.

$\begin{array}{cccc}\begin{array}{c}\text { Sampling } \\ \text { time }\end{array} & \begin{array}{c}\text { Total dust } \\ \text { concen- } \\ \text { (minutes) } \\ \text { tration } \\ \left(\mathrm{mg} / \mathrm{m}^{3}\right)\end{array} & \begin{array}{c}\text { Aluminum } \\ \text { concen- } \\ \text { tration } \\ \left(\mathrm{mg} / \mathrm{m}^{3}\right)\end{array} & \begin{array}{c}\text { Respira- } \\ \text { tory pro- } \\ \text { tection }\end{array} \\ & & \end{array}$

\begin{tabular}{|c|c|c|c|c|c|}
\hline \multicolumn{6}{|c|}{ Worker A (fitting) } \\
\hline Day 1 & 259 & 7.9 & 2.2 & No & \multirow{2}{*}{$\begin{array}{l}\text { Confined } \\
\text { compartment }\end{array}$} \\
\hline Day 2 & 355 & 0.4 & 0.02 & Yes $^{a}$ & \\
\hline \multicolumn{6}{|c|}{ Worker B (welding) } \\
\hline Day 1 & 372 & 0.2 & 0.008 & Yes $^{b}$ & \\
\hline Day 2 & 392 & 0.7 & 0.09 & Yes $^{b}$ & \\
\hline \multicolumn{6}{|c|}{ Worker C (welding) } \\
\hline Day 1 & 368 & 3.7 & 1.5 & Yes $^{a}$ & \\
\hline Day 2 & 282 & 13.6 & 6.1 & No & \\
\hline \multicolumn{6}{|c|}{ Worker D (welding) } \\
\hline Day 1 & 382 & 0.3 & 0.04 & Yes $^{b}$ & \\
\hline Day 2 & 366 & 0.3 & 0.01 & $Y_{e s}^{b}$ & \\
\hline \multicolumn{6}{|c|}{ Worker E (fitting) } \\
\hline Day 1 & 384 & 5.8 & 2.3 & No & \\
\hline Day 2 & 326 & 9.4 & 3.1 & No & Plasma cutting \\
\hline \multicolumn{6}{|c|}{ Worker F (fitting) } \\
\hline Day 1 & 340 & 10.0 & 2.4 & Yes $^{a}$ & Semiconfined \\
\hline Day 2 & 415 & 2.2 & 0.4 & Yes $^{a}$ & compartment \\
\hline \multicolumn{6}{|c|}{ Worker G (fitting) } \\
\hline Day 1 & 340 & 5.7 & 1.5 & No & \\
\hline Day 2 & 355 & 1.2 & 0.3 & No & \\
\hline \multicolumn{6}{|c|}{ Worker H (fitting) } \\
\hline Day 1 & 280 & 10.7 & 3.0 & No & Plasma cutting \\
\hline Day 2 & 385 & 2.3 & 0.4 & No & \\
\hline \multicolumn{6}{|c|}{ Worker I (fitting) } \\
\hline Day 1 & 290 & 0.4 & 0.04 & Yes $^{a}$ & \\
\hline Day 2 & 395 & 1.0 & 0.2 & Yes $^{a}$ & \\
\hline \multicolumn{6}{|c|}{ Worker J (welding) } \\
\hline Day 1 & 371 & 0.5 & 0.07 & Yes $^{a}$ & \\
\hline Day 2 & 400 & 1.3 & 0.3 & $Y_{e s}{ }^{a}$ & \\
\hline \multicolumn{6}{|c|}{ Worker K (welding) } \\
\hline Day 1 & 362 & 2.8 & 0.8 & Yes $^{\mathrm{a}}$ & Confined \\
\hline Day 2 & 160 & 1.4 & 0.4 & Yes $^{\mathrm{a}}$ & compartment \\
\hline \multicolumn{6}{|c|}{ Worker L (welding) } \\
\hline Day 1 & 330 & 0.6 & 0.2 & Yes $^{a}$ & Semiconfined \\
\hline Day 2 & 410 & 0.4 & 0.02 & Yes $^{\mathrm{a}}$ & compartment \\
\hline
\end{tabular}

${ }^{a}$ Air-filtering respirator with a battery-powered pump.

${ }^{b}$ Respirator connected to the compressed air system.

\section{Airborne exposure}

In welding and fitting operations at the shipyard, the mean 8-hour TWA concentration in the personal air samples was 3.5 (range $0.3-13.6$ ) $\mathrm{mg} / \mathrm{m}^{3}$ for total dust and 1.1 (range $0.008-6.1) \mathrm{mg} / \mathrm{m}^{3}$ for aluminum (table 1). Aluminum constituted an average of $32 \%$ of the total dust mass. High concentrations were encountered during welding in enclosed compartments and in plasma cutting. Worker A volunteered not to use respiratory protection on study day I, as did worker $\mathrm{C}$ in the afternoon of study day II. As expected, nonuse of respiratory protection had a marked impact on the exposure, the difference in the inhaled aluminum concentration between the two workdays being 100 -fold in the first case and 4-fold in the second (table 1).

In the aluminum sulfate plant, the mean 8-hour TWA concentrations in the personal air samples was 1.3 (range $0.3-4.4) \mathrm{mg} / \mathrm{m}^{3}$ for total dust and 0.13 (range $0.02-0.5$ ) $\mathrm{mg} / \mathrm{m}^{3}$ for aluminum (table 2). The average content of aluminum in total dust was about $10 \%$. The highest concentrations of airborne contaminants were found for workers in charge of maintenance and bagging due to their exposure during the repair of blocked tubing.

\section{Aluminum in biological samples of workers and refer- ence groups}

Table 3 shows the concentrations of aluminum measured in the serum and urine samples obtained at the end of the shift from the shipyard workers and aluminum sulfate plant workers and during the subsequent summer vacation. Corresponding concentrations measured for local

Table 2. Airborne 8-hour time-weighted concentrations of total dust and aluminum measured in the respiratory zone of the aluminum sulfate plant workers.

\begin{tabular}{lcccl}
\hline & $\begin{array}{c}\text { Sampling- } \\
\text { time } \\
\text { (minutes) }\end{array}$ & $\begin{array}{c}\text { Total dust } \\
\text { concentration } \\
\left(\mathrm{mg} / \mathrm{m}^{3}\right)\end{array}$ & $\begin{array}{c}\text { Aluminum- } \\
\begin{array}{c}\text { concentration } \\
\left(\mathrm{mg} / \mathrm{m}^{3}\right)\end{array}\end{array}$ & Remarks \\
\cline { 2 - 5 } & (reactor management) & & \\
Worker & 403 & 0.3 & 0.02 & \\
Day 1 & 489 & 0.3 & 0.02 & \\
Day 2 & 389 & & \\
Worker 2 & (granulating) & & & \\
Day 1 & 410 & 0.7 & 0.2 & \\
Day 2 & 358 & 0.5 & 0.03 & \\
Worker 3 & (bagging) & & & \\
Day 1 & 380 & 2.2 & 0.3 & Opening of blocked \\
Day 2 & 373 & 0.9 & 0.06 & tubing \\
Worker 4 (maintenance) & & & \\
Day 1 & 404 & 4.4 & 0.5 & Opening of blocked \\
Day 2 & 384 & 1.9 & 0.08 & tubing \\
Worker 5 & (in-plant transport) & & \\
Day 1 & 409 & 1.0 & 0.05 & \\
Day 2 & 369 & 0.4 & 0.02 & \\
\hline
\end{tabular}


Table 3. Concentration of aluminum in serum and urine in the exposure groups at the shipyard and the aluminum sulfate plant, as well as in occupationally unexposed reference groups.

\begin{tabular}{|c|c|c|c|c|c|c|c|c|}
\hline \multirow[t]{2}{*}{ Group } & \multirow[t]{2}{*}{$\mathrm{N}$} & \multirow[t]{2}{*}{$\begin{array}{l}\text { Mean age } \\
\text { (years) }\end{array}$} & \multicolumn{2}{|c|}{$\begin{array}{l}\text { Postshift serum aluminum } \\
\text { concentration }(\mu \mathrm{mol} / \mathrm{l})\end{array}$} & \multicolumn{2}{|c|}{$\begin{array}{l}\text { Postshift urinary aluminum } \\
\text { concentration ( } \mu \mathrm{mol} / \mathrm{l})\end{array}$} & \multicolumn{2}{|c|}{$\begin{array}{l}\text { Vacation urinary aluminum } \\
\text { concentration }(\mu \mathrm{mol} / \mathrm{l})\end{array}$} \\
\hline & & & Mean & Range & Mean & Range & Mean & Range \\
\hline Welders and fitters $(A)$ & 12 & 34 & 0.22 & $0.03-0.46$ & 3.4 & $0.46-12.0$ & 2.6 & $0.63-7.9$ \\
\hline Aluminum sulfate workers (B) & 5 & 46 & 0.13 & $0.08-0.19$ & 0.58 & $0.16-1.41$ & 0.46 & $0.27-0.80$ \\
\hline Local referents for $A$ & 12 & 41 & 0.07 & $0.04-0.11$ & 0.60 & $0.24-1.5$ & .. & .. \\
\hline Local referents for $B$ & 6 & 44 & 0.11 & $0.07-0.12$ & 0.31 & $0.19-0.61$ & .. &.. \\
\hline City referents ${ }^{a}$ & & & 0.06 & $0.02-0.13$ & 0.33 & $0.07-0.82$ & .. &.. \\
\hline
\end{tabular}

a Serum samples: 12 women and 9 men, mean age 39 years; urine samples: 28 women and 16 men, mean age 40 years.
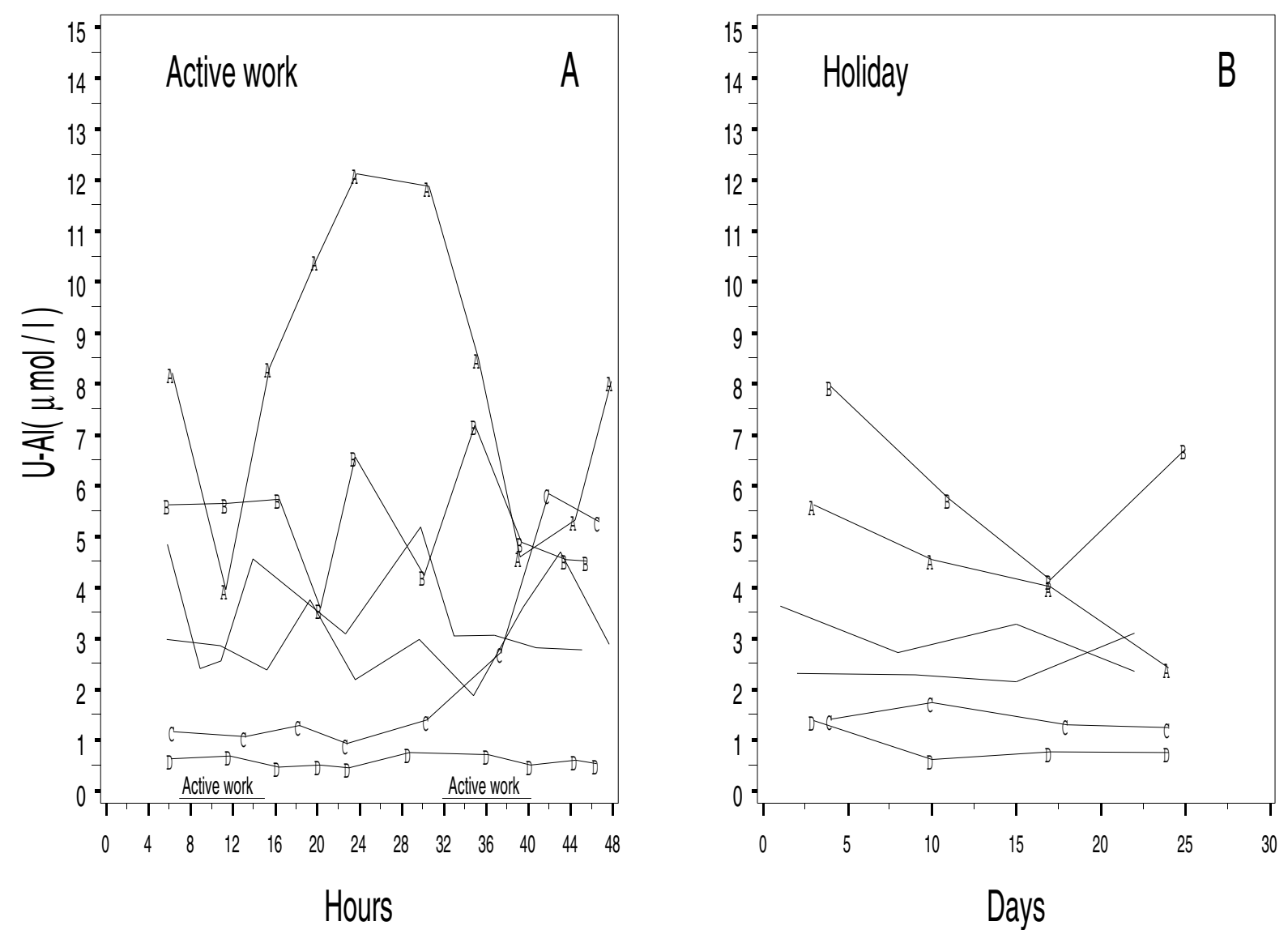

Figure 1. Behavior of urinary aluminum in consecutive urine voids of six aluminum welders or fitters over 2 days of active work (A) and in weekly samples over a summer vacation some weeks later (B).

referents and in a larger control group (employees of the Finnish Institute of Occupational Health from three main Finnish cities) are also given.

\section{Relation between aluminum in ambient air and in biological samples}

There was a fair correlation between the 8-hour TWA aluminum concentration in ambient air and the serum aluminum concentration in the sample taken at the end of the shift among the shipyard workers ( $\mathrm{r}=0.60)$, but the correlation was poor between aluminum in air and the amount of aluminum excreted in urine over the shift and the subsequent 16 hours. The latter finding was readily explained by the fact that some of the welders or fitters excreted large amounts of aluminum in their urine despite minimal concentrations of aluminum in the air inhaled during the study days.

Figure 1, part A, illustrates the behavior of the urinary aluminum of six shipyard workers over the 
two study days. Worker A experienced heavy exposure to welding fumes on study day I, as he volunteered to use the welding helmet without respiratory protection-the normal arrangement in aluminum welding at earlier times in the shipyard-resulting in the highest urinary aluminum levels among the six welders or fitters for about 24 hours. Worker B exhibited a zigzag of fairly high urinary aluminum levels over the whole observation period although his measured exposure to airborne aluminum was minimal. Worker $\mathrm{C}$ volunteered to participate in an intentional aggravated exposure by not using respiratory protection during welding in the afternoon of study day II. His previously low level of urinary aluminum increased abruptly to a five times higher peak concentration after the end of the shift, and this peak had not yet normalized by the next morning. Worker D had carefully used respiratory protection throughout his 4-year history of aluminum welding. The efficiency of his protection was verified by the very low aluminum concentrations measured in his breathingzone air samples. He persistently showed the lowest urinary aluminum concentrations of the whole group. To make the graphic presentation clearer, results of only two additional members of the exposure group are given in figure 1 , part $\mathrm{A}$, representing welders or fitters that exhibited moderate urinary aluminum concentrations. Three weeks later, all of the welders and fitters went on a 4-week summer vacation. Figure 1, part B, shows the behavior of the aluminum concentration in four weekly urine samples of the same six workers. Workers A and $\mathrm{B}$ had the highest urinary aluminum levels at the start However, for worker A, the concentration was halved in less than 4 weeks, whereas for worker B there was no consistent change. Worker $\mathrm{C}$ resumed the relatively low stable concentrations observed during and after study day I, and his colleague D continued to exhibit the same low aluminum levels as when he performed welding.

Among the aluminum sulfate workers, the urinary aluminum concentration during work (figure 2, part A; note the different scale on the Y-axis compared with that of figure 1) and over the vacation (figure 2, part B) displayed a rather similar profile of low concentrations for all of the workers. Some workers exhibited slight transient elevations of urinary aluminum during active work, which may indicate the uptake of aluminum.

\section{Behavior of aluminum in biological samples over time}

After study day I, the median serum aluminum concentration in the group of 12 welders and fitters decreased
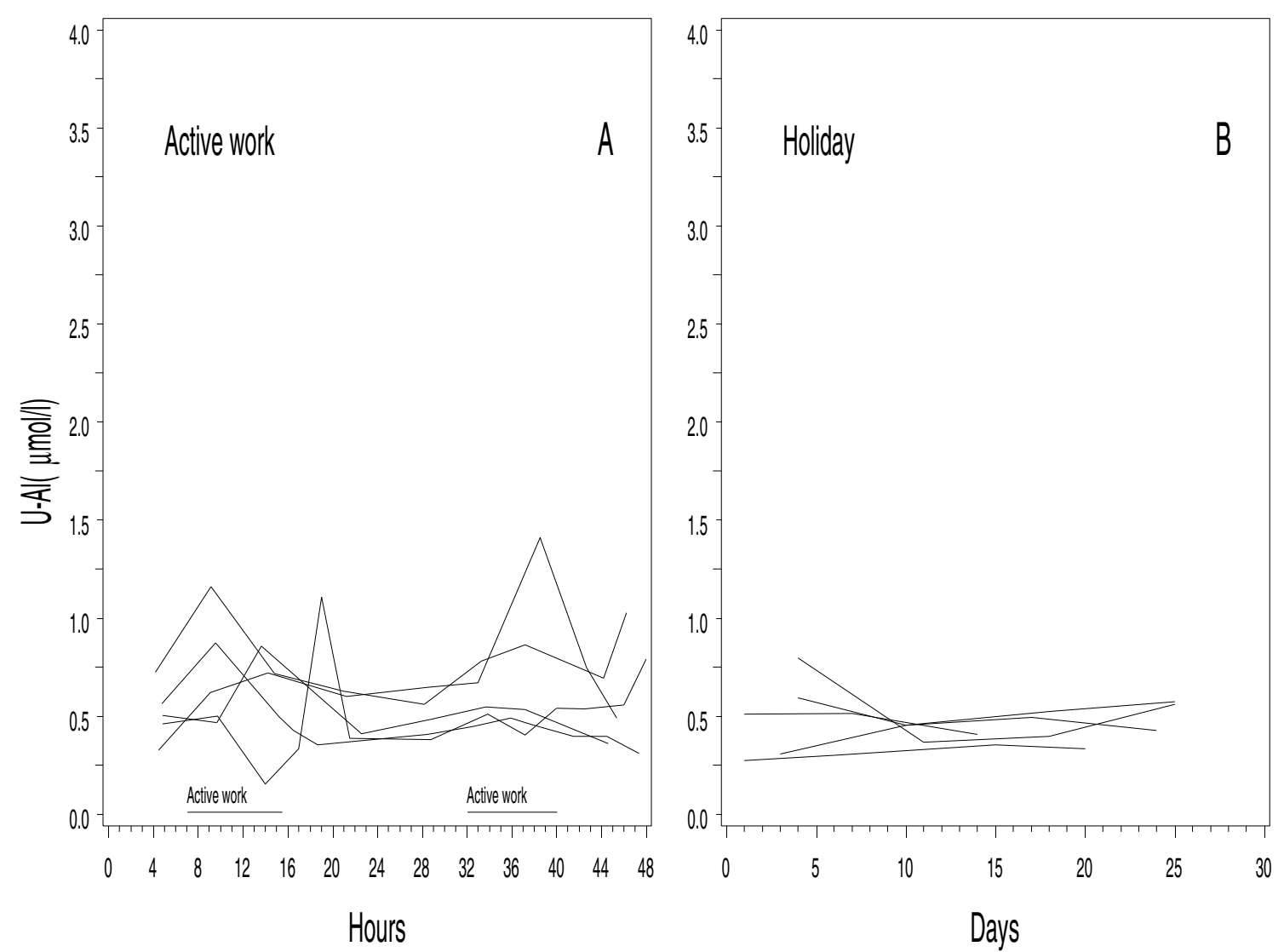

Figure 2. Behavior of urinary aluminum in consecutive urine voids of five aluminum sulfate workers over 2 days of active work $(A)$ and in weekly samples over a summer vacation some weeks later (B). Note the different scale for the $y$-axis compared with that of figure 1. 
by about $50 \%$ (t-test for paired samples, $\mathrm{P}<0.01$ ) overnight in 16 hours. In contrast, the concentration of aluminum in the corresponding urine samples from the same workers did not show any consistent change $(\mathrm{P}=0.64)$. As regards the five aluminum sulfate plant workers, there were no trends of change overnight after study day I either for the serum aluminum or urinary aluminum concentration. It is however worth noting

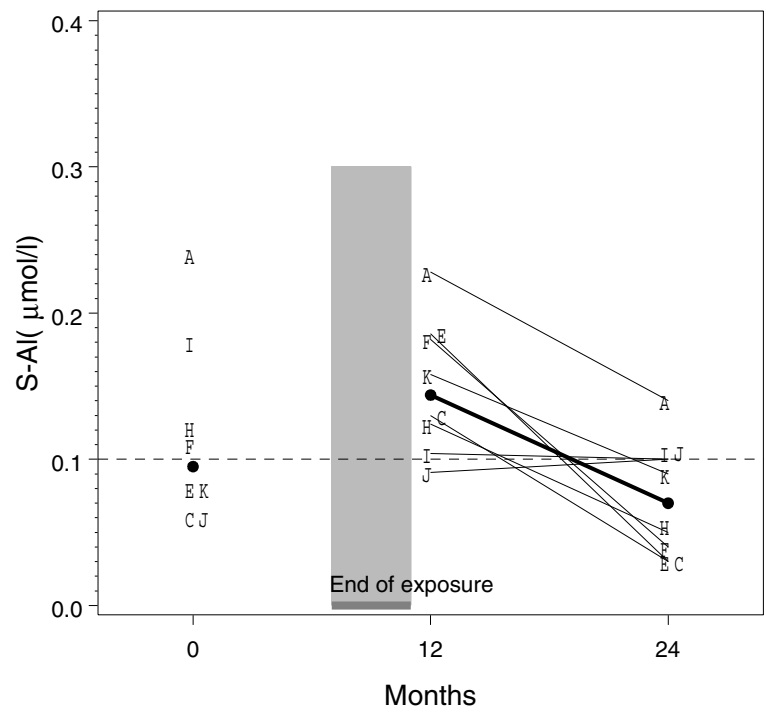

Figure 3. Serum aluminum concentration (S-Al) of eight aluminum welders or fitters in a preshift sample, as well as 12 and 24 months later when aluminum welding had ceased. Each worker is denoted by a letter; bold markings indicate median values. The broken horizontal line shows the 95th percentile of the normal distribution of serum aluminum in occupationally unexposed Finnish residents.

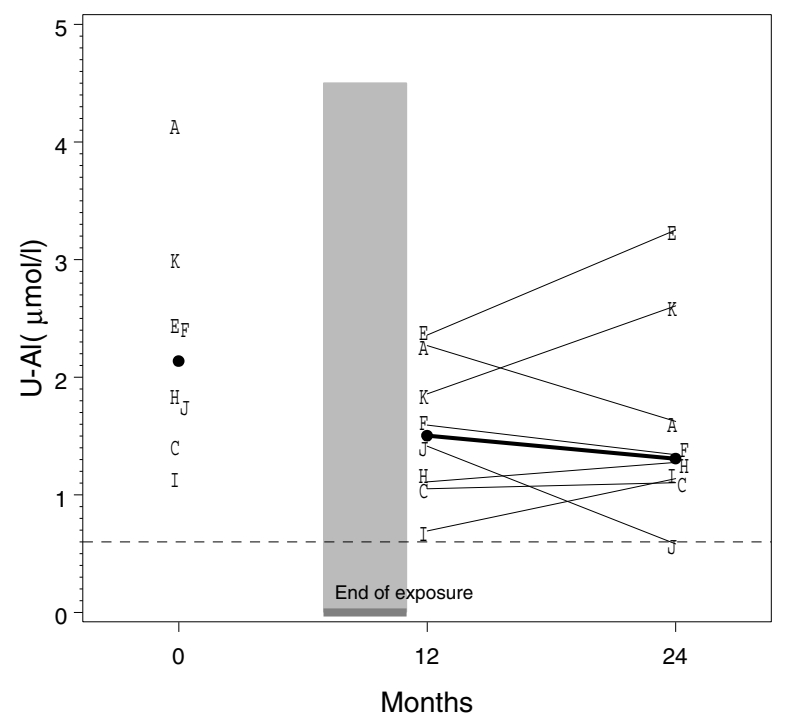

Figure 4. Urinary aluminum concentration (U-Al) of eight aluminum welders or fitters during a summer vacation (mean of weekly samples), as well as 12 and 24 months later when aluminum welding had ceased. Each worker is denoted by a letter. The broken horizontal line shows the 95th percentile of the normal distribution of urinary aluminum in occupationally unexposed Finnish residents. that, compared with the corresponding value of the welders and fitters, their serum aluminum concentration was relatively higher than the urinary aluminum concentration.

A follow-up of the serum and urinary aluminum concentrations for 2 years was possible only for the shipyard workers, and a complete series of samples was obtained from eight welders or fitters (figures 3 and 4). The starting point (month 0 ) for the serum aluminum concentration was the concentration in a preshift sample during active work; for the urinary aluminum, it was the mean urinary aluminum concentration in 4 weekly samples during the subsequent holiday. At the 12-month time point (welding with aluminum had stopped 1-5 months earlier), the mean values of aluminum in the serum and urine samples obtained before and after a 4-week vacation were used and, at 24 months, aluminum was measured in the preshift serum and urine sample of the same day. At the start, the median aluminum concentration in the morning serum sample was low relative to the median concentration of the urinary aluminum concentration. This result raises the question of whether equilibrium was disturbed by the prior rapid clearance. At 12 months, the concentrations in the samples taken before and after a 4-week vacation showed the same pattern of distribution for the welders and fitters and slight decreases over the vacation for the aluminum concentrations of the aluminum sulfate workers (figure 5). The time period 12-24 months mirrors the elimination or excretion of aluminum from the body, albeit in this case roughly, because it is covered by only two points of measurement. The serum aluminum concentration decreased significantly $(\mathrm{P}=0.007)$, and the median concentration

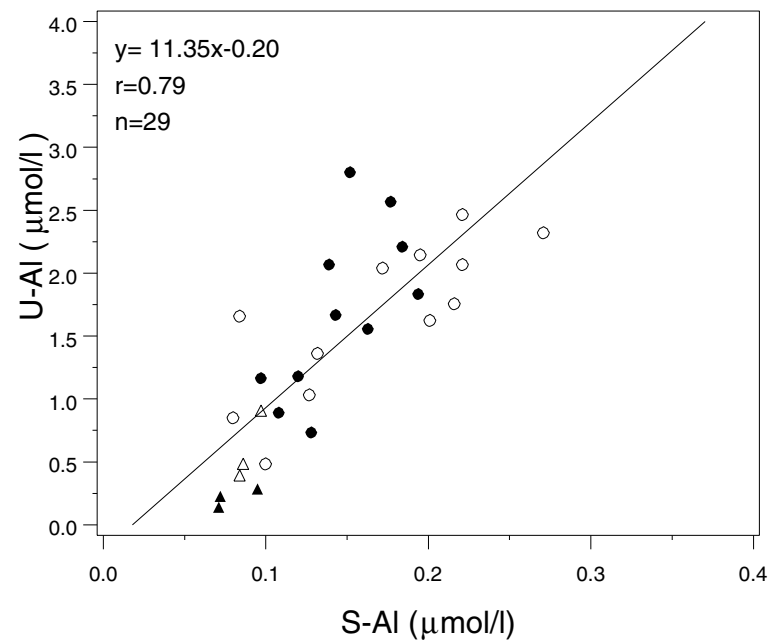

Figure 5. Correlation of the serum (S-Al) and urinary (U-Al) aluminum concentrations of 12 aluminum welders or fitters (round symbols) with three aluminum sulfate workers (triangles) sampled after 1 year of follow-up before (open symbols) and after (closed symbols) the 4-week summer vacation. 
was halved in approximately 1 year, whereas there was no change $(\mathrm{P}=0.75)$ in the corresponding concentration of aluminum in urine. The broken lines in figures 3 and 4 denote the 95th percentiles of the normal distribution of serum or urinary aluminum in Finnish adult city residents without occupational exposure to aluminum (7). Thus, for most of the workers, the serum aluminum concentration had fallen to the normal range at the end of the follow-up, contrary to the situation with the urinary aluminum concentration.

\section{Relationship between the serum aluminum and urinary aluminum concentrations}

A significant correlation was found between aluminum concentrations in serum and urine at the end of the shift $(r=0.74)$ and 1 year later when the welders and fitters were no longer exposed to aluminum (figure 5). In the preshift samples, the correlation between the serum (S$\mathrm{Al})$ and urinary (U-Al) aluminum concentrations was poorer, and the regression line was much steeper than the aforementioned ones (data not shown). The latter observation implies that the $\mathrm{U}-\mathrm{Al} / \mathrm{S}-\mathrm{Al}$ ratio changed with time, being (at a U-Al concentration of $3 \mu \mathrm{mol} / \mathrm{l}$ ) about 25 for the preshift samples, about 14 for the postshift samples, and about 11 for the samples taken 1 year later. Moreover, it can be seen in figure 5 that the U-Al/S-Al ratio of the samples from the aluminum sulfate workers, who exhibited concentrations in the upper normal range (U-Al around $0.5 \mu \mathrm{mol} / \mathrm{l}$ ), was about 6 .

\section{Discussion}

Matczak \& Gromiec (1) investigated the environmental exposure of welders and fitters working on the same type of aluminum alloy and with the same (MIG) welding method as in this study. Their unprotected workers experienced similar levels of airborne aluminum as our unprotected workers, and the contribution of aluminum to total dust was $30 \%$, as in our study. In the personal air samples that were collected from outside of the welding helmet, the respirable fraction of the total dust was less than half; this finding may at least partly be attributed to grinding, which produces larger particles than welding. Nonrespirable particles were less likely to enter the breathing zone of our workers, who used respiratory protection.

Hull \& Abraham (6) described two cases of pneumoconiosis induced by aluminum welding fumes. The men had been employed as welders or welder-grinders at a shipyard for more than 20 years without using any respiratory protection. A postmortem examination of their lungs revealed fibrosis and interstitial or alveolar aggregates of macrophages with cytoplasm containing extremely fine particulate matter. An analysis of the lung tissue with scanning (SEM) and transmission (TEM) electron microscopy, as well as an energy dispersive $\mathrm{X}$ ray analysis, showed an extremely high number of inorganic particles (average $8.55 \times 10^{9}$ particles $/ \mathrm{cm}^{3}$ tissue). Approximately $86 \%$ of them were metallic particles, all containing aluminum. The average diameter of the aluminum particles was $0.34 \mu \mathrm{m}$, but the TEM analysis showed that many of the particles were aggregates, and singlet particles as small as $10 \mathrm{~nm}$ in diameter were discovered. The particulate matter in the lungs concurs with the characteristics of the welding fumes in our study.

The toxicokinetics of aluminum in humans has been characterized after administration by the oral or intravenous route (8), whereas inhalation, which is the main exposure route in the occupational setting, has not received similar attention. Aluminum is the third most common element in the earth's crust, occurring naturally in insoluble compounds within minerals. Aluminum is not essential for living organisms and causes toxicity at high concentrations. In view of its ubiquitous presence in the environment and its potential toxicity, it should not be surprising that the element is poorly absorbed from the gastrointestinal tract. Thus only about $0.1 \%$ of insoluble aluminum species is taken up from the intestine. However, coordination complexes of aluminum with organic acids, notably citrate, are absorbed more efficiently.

While the human intestinal wall functions as a protective barrier, no such protection from soluble aluminum compounds is offered by the alveolocapillary membrane of the lung (8). A minor part of the aluminum in fresh welding fumes-presumably the smallest particles-is rapidly taken up in the lungs to the systemic circulation. The majority of welding fume particles constitutes sparsely soluble or insoluble particles that are slowly and incompletely absorbed upon solubilization inside phagocytic macrophages unless they become subject to more-rapid-acting mechanical removal by the mucociliary system, which transports them up in the airways to the throat to become ultimately swallowed. After two volunteers had inhaled respirable particles of insoluble ("aged") ${ }^{26}$ aluminum oxide, only $0.02 \%$ of the dose deposited in the lung was cleared (absorbed and excreted) each day in the urine (8), and the cumulative excretion over a period of 900 days was $1.9 \%$. If we assume that our group of welders and fitters, after 4 years of welding with aluminum, were approaching a steady state for aluminum in most tissues (whereby daily uptake equals daily excretion), we can try to estimate the absorbed fraction from the daily intake of aluminum and the 24-hour urinary excretion because aluminum is excreted almost entirely via urine. The estimation is complicated by uncertainty about the overall degree of alveolar deposition for welding fume particles, with 
sizes possibly ranging over two orders of magnitude $(0.01-1 \mu \mathrm{m})$. According to the model of the International Commission on Radiological Protection (ICRP) (9), the corresponding alveolar deposition fractions range from $50 \%$ for the smallest particles down to $10 \%$ for the largest particles. For the estimation, we chose to use an arbitrary figure of $20 \%$. In the 21 cases in which the personal daily exposure to aluminum, as well as the excretion of aluminum in urine, was measured, the mean alveolar deposition of freshly generated aluminum fumes was $2.2 \mathrm{mg}(81.5 \mu \mathrm{mol})$, on the assumption of the use of $10 \mathrm{~m}^{3}$ ventilation. The corresponding mean amount of aluminum excreted in 24-hour urine was 4 $\mu \mathrm{mol}$; this value would suggest that $4.9 \%$ of the alveolar deposition was absorbed and excreted. This conclusion is, however, flawed by the long-term accumulation of aluminum in the lungs, which serves as a reservoir for systemic absorption on top of current inhalation exposure. The case of worker C (figure 1, part A) can help to distinguish the roles of lung burden and current exposure in aluminum uptake. Worker $\mathrm{C}$ exhibited a stable urinary aluminum excretion at a relatively low level on the first day of the investigation, consistent with his moderate current exposure and low lung burden (figure 1, part B). On the second day, at high exposure, the estimated alveolar deposition of aluminum was $12.2 \mathrm{mg}(452 \mu \mathrm{mol})$, and the corresponding 24-hour excretion of aluminum in urine was $5.6 \mu \mathrm{mol}$, a finding suggesting that $1.2 \%$ of the inhaled aluminum was taken up rapidly. Even this figure is a slight overestimation because the (minor) impact of the lung burden was not accounted for.

For the aluminum sulfate plant workers, the corresponding estimate for the mean daily alveolar deposition was $0.13 \mathrm{mg}(4.8 \mu \mathrm{mol})$ on the assumption of a $10 \%$ deposition on the basis of particle size (9). Their mean 24-hour excretion of aluminum in urine was $0.64 \mu \mathrm{mol}$. However, in the morning urine samples, the local controls exhibited $50 \%$ of the concentration determined for the aluminum sulfate workers; therefore, a reduction by $50 \%$ is needed to distinguish an occupational aluminum source from other (dietary) aluminum sources. For the average daily excretion of aluminum in urine among the general population, Priest (8) gave $7.5 \mu \mathrm{g}(0.28 \mu \mathrm{mol})$, which is in line with our estimate for control persons. The calculation of the absorbed fraction would suggest that $6.7 \%$ of the aluminum deposited in the alveoli was taken up. As the workers exhibited completely normal values of urinary aluminum during their summer vacation (figure 2, part B), there were no lung burdens of aluminum to confuse the issue, whereas a previous history of two decades of exposure must have caused an increased body burden of aluminum in the skeleton. [See the later discussion.] Conclusions about the absorbed fraction are however hampered by the turnover of aluminum in the bone (albeit at a low rate), by the uncertainty of the magnitude of alveolar deposition (deposition has an inverse relationship to the absorbed fraction), and by the actual aluminum species involved. The predominant compounds in the dust at the plant were bauxite and aluminum sulfate. Although aluminum sulfate is water soluble, in aquatic systems at physiological $\mathrm{pH}$, trivalent aluminum undergoes hydrolysis, forming insoluble aluminum hydroxide $\left[\mathrm{Al}(\mathrm{OH})_{3}\right]$ precipitate. However, in blood plasma and the interstitial fluid of tissues, hydrolysis is completely inhibited by complexing organic acid anions [eg, citrate, or transferrin (8)]. In blood plasma, transferrin binds about $90 \%$ of aluminum, while the remaining part is bound to low-molecular-mass species, mainly citrate. While aluminum sulfate is likely to precipitate in the airway mucosa and become cleared, like bauxite particles, by the mucociliary escalator, dissolved aluminum from particles deposited on the respiratory epithelium in close proximity to interstitial fluid may be complexed with organic molecules and thus retain the ability to pass across the respiratory epithelium.

Sjögren et al (2) exposed three previously unexposed volunteers to the MIG welding fumes of aluminum for 1 day and six professional aluminum welders to similar welding fumes over 1 workweek. They made the remarkable observation that, among the unexposed volunteers, the urinary aluminum concentration rose from the preexposure level $(0.1 \mu \mathrm{mol} / \mathrm{l})$ up to $15 \mu \mathrm{mol} / \mathrm{l}$, peaking soon after the end of the exposure, and then declined with a half-time of about 8 hours. The authors estimated that the previously unexposed volunteers excreted $0.1-0.3 \%$ of the total inhaled dose in their urine within the next 2 days. For the estimation, the authors assumed, however, that all of the aluminum in the inhaled air was deposited in the lungs, and therefore a five times greater systemic absorption would be more appropriate, yielding a figure similar to our estimate. Among the professional welders, those who had a work history of 2 years or more and had the highest urinary aluminum levels $(1.6-13.6 \mu \mathrm{mol} / \mathrm{l})$ during the unexposed weekend did not show any consistent increase of their urinary aluminum concentration during or immediately after the exposures, and neither did they show any decline during the following weekend. Hence, aluminum in urine depended partly on the current exposure, as indicated by the previously unexposed volunteers and partly by the duration of past exposure (and accumulated lung burden thereof) as indicated by the long-term welders. A subsequent study by the same authors (4) demonstrated that, among welders exposed for less than 1 year, the elimination half-time for aluminum in urine was about 9 days, whereas, among the welders exposed for more than 10 years, the urinary half-time was 6 months or longer.

We followed the behavior of serum aluminum over a 16-hour period after the workshift and found that the median aluminum concentration for 12 workers 
decreased by $50 \%$; this finding indicates that the previous day's aluminum uptake was rapidly cleared by tissue distribution and excretion. In contrast, the aluminum concentration in the corresponding urine samples did not show a consistent change. In the second year of follow up, when aluminum welding had ceased altogether, the median serum aluminum concentration of eight welders and fitters was halved within 1 year, the finding indicating slow kinetics of the element. The corresponding aluminum concentration in urine was not significantly decreased; this finding demonstrates that the half-time for aluminum excretion in urine is longer than 1 year for long-term welders.

Aluminum is concentrated in bone tissue, and, due to the slow turnover of bone, the element is retained in the human skeleton for a long time. For two aluminum welders with a 20-year exposure history, the aluminum concentrations in whole blood and urine were measured four times over 9 years that included a 5 -year postwelding period (10). The aluminum concentration in blood varied between 4 and $53 \mu \mathrm{g} / \mathrm{l}(0.15$ and $2.0 \mu \mathrm{mol} / \mathrm{l})$, and the corresponding urinary aluminum varied between 107 and $351 \mu \mathrm{g} / \mathrm{l}(4.0$ and $13.0 \mu \mathrm{mol} / \mathrm{l})$. The determination of aluminum in biopsy samples from the iliac bone on the last occasion of measurement ( 5 years after welding had ceased) gave a value of $18-29 \mu \mathrm{g} / \mathrm{g}$ dry weight. This level was about one-fourth of the highest concentration that the authors had encountered in renal patients on dialysis (10) and is about one-tenth of the level reported for patients suffering from aluminum-induced dialysis encephalopathy. In the latter patients, the brain showed 10 times lower concentrations than bone (8). Concerning aluminum welders, no data were found of aluminum concentrations in tissues other than bone.

Observations from volunteer studies with intravenously injected ${ }^{26}$ aluminum citrate enabled the authors to construct a biokinetic model for aluminum retention (8). According to the model, among the six tissue compartments, of which four concerned bone, aluminum has a long retention half-time only in trabecular bone mineral (half-time $=500$ days) and cortical bone mineral (halftime $=10500$ days); thus accumulation in cortical bone would take place throughout a worker's lifetime. Retention similar to that in bone, and hence accumulation, is believed to apply to aluminum in the brain, although conclusive data are lacking (8). Although accumulation over decades leads to a large body burden of aluminum in the skeleton, the authors concluded that, due to the low transfer rates involved, only about $2 \%$ of aluminum entering the blood is retained within the body for years; the remainder is excreted in urine.

Thus, among welders and fitters, unlike among aluminum sulfate workers, the accumulation of sparsely soluble aluminum in the lungs (lung burden) plays the dominant role in the concentrations of aluminum in serum and urine shortly after the most current uptake has been washed out. In a group of long-term aluminum welders, both the serum and urinary aluminum concentrations correlated directly with the duration of exposure; this finding demonstrates the development of the lung burden (11). Lung burden is a reservoir for systemic aluminum uptake for many years postexposure, and slow mobilization of the lung burden is presumably rate limiting for the urinary excretion of aluminum in the later postexposure phase.

Interestingly, while the ratio of urinary aluminum to serum aluminum is somewhere around 6 for the general population, as it was also for the modestly exposed aluminum sulfate workers, the ratio was two times higher for the aluminum welders and fitters. In a previous study on 84 long-term welders of aluminum or mild steel, the serum and urinary aluminum concentrations were correlated in that, at a urinary aluminum concentration of $0.6 \mu \mathrm{mol} / \mathrm{l}$, the ratio of urinary aluminum to serum aluminum was 6 , while the corresponding ratios at urinary aluminum concentrations of $3 \mu \mathrm{mol} / \mathrm{l}$ and $10 \mathrm{~mol} / \mathrm{l}$, the corresponding ratios were 14 and 25 (11). Thus it appears that the clearance of aluminum in serum is concentration dependent. Changes in the speciation of aluminum in serum at high concentrations (eg, a greater fractional complexation of aluminum with the ultrafiltrable citrate) could possibly be the underlying factor. In renal patients on dialysis, the ultrafiltrable fraction of plasma aluminum was as high as $50 \%$, whereas the normal level is about $10 \%$ (12).

The conventional form of biological monitoring determines the concentration of a toxicant in blood or urine that accurately reflects the magnitude of internal systemic exposure and that, hopefully, has an important bearing on health risk. The current approaches to the biological monitoring of aluminum in the occupational setting (eg, the determination of aluminum in plasma or serum or in urine) do not meet the stated criteria, essentially because the critical accumulation of aluminum in the target organs of toxicity, bone tissue and the brain cannot be assessed from the concentration of aluminum in serum or urine in occupational groups, the underlying reason being that these aluminum stores have a small impact on the aluminum concentration in serum and urine due to the slow transfer rates. In contrast, serum aluminum plays an important role in the monitoring of uremic renal patients who are at danger of massive aluminum uptake from the use of contaminated water in dialysis (a danger of the past) and the use of aluminum compounds in medication, aggravated by the inability of the patients to excrete the element normally via diseased kidneys, all of these factors resulting, in the long run, in high aluminum levels in tissues and organs.

This study and many previous ones $(2-5,11,13,14)$ show that exposure to aluminum welding fumes can be 
of concern because the intake can lead to significant rapid systemic absorption of aluminum and, in the long term, to the development of a remarkable lung burden, as well as to an abnormally large body burden in the skeleton. The concern also applies to other processes involving the generation of vapor condensation fumes of aluminum (arc spraying, plasma cutting), as well as to the manufacture of finely divided aluminum powder $(3,15-17)$. This study and a previous one (3) did not suggest that similar concerns would arise in inhalation exposure to aluminum sulfate particles when the chemical is manufactured. It should be noted, however, that the low measured serum and urinary aluminum levels of the aluminum sulfate workers do not preclude an increased body burden in the skeleton that would be a logical consequence of exposure for two decades. It follows that the health and safety surveillance of workers would benefit from biological monitoring in the case of aluminum welding, but not in the latter case. The rapid uptake of aluminum in a welding type of activity can be verified by the analysis of aluminum in serum or urine sampled at the end of the workshift. The determination can be useful to confirm the safety of the methods used, including confirmation of the efficiency of respiratory protection, but it lacks significance for health. Given that one waits over an exposure-free weekend before the sampling, one can estimate the lung burden from serum and urine aluminum concentrations that result from the dissolution or mobilization of the element from particles, consequent systemic uptake, and excretion. Apparently, both serum aluminum and urinary aluminum are equally valid markers of lung burden at the time of contemporary exposure because they correlate with each other. However, urinary aluminum is a more sensitive marker of internal load (16) in that, after repeated exposures at low ambient levels of aluminum, the serum aluminum concentration can be completely normal, whereas the concurrent urinary aluminum concentration is clearly increased or, as shown in this study, within about a year after terminated exposure, the serum aluminum concentration of many ex-welders had decreased to the normal range but urinary aluminum had not. Thus, while the measurement of aluminum in the urine is recommended for the monitoring of the accumulation of - or preferably, of course, absence thereof-aluminum in the body, it is not expected that the measurement of urinary aluminum is useful in verifying the efficacy of exposure abatement; the analysis of aluminum in serum would be a better choice for this purpose.

Currently we do not have sufficient data to draw conclusions about the health consequences of the lung burden of aluminum. While severe local effects in the lung are unlikely events, the lung burden as a reservoir for the further systemic uptake of aluminum many years into the future is worrying in view of the markedly increased bone aluminum found after 20 years of welding. Bone tissue and the brain are the critical organs of aluminum toxicity. As long as we do not have a clear picture of the relationship between the lung burden of aluminum and aluminum concentrations in the sensitive target organs, we cannot address the concern for health risks properly. As noninvasive methods for aluminum analysis in bone and brain may not be soon forthcoming, it would be extremely valuable if, following appropriate ethical and legal procedures, an opportunity should arise to determine target organ aluminum concentrations with conventional, modern methods ex vivo. In the meantime, monitoring of the lung burden in aluminum welders is practical through the use of the analysis of aluminum in urine, and hygienic limits can be set as guidelines for acceptable and nonacceptable burdens. The Finnish Institute of Occupational Health has recommended the biological action level of $6 \mu \mathrm{mol} / \mathrm{l}(162 \mu \mathrm{g} / \mathrm{l})$ for aluminum in urine sampled after an exposure-free weekend (18). Germany has established a biological tolerance value of $200 \mu \mathrm{g}$ aluminum/l in postshift urine for occupational exposure (19). Successful prevention of the development of excessive urinary aluminum levels should dispel all major concerns about adverse health effects from exposure to aluminum.

\section{Acknowledgments}

We are greatly indebted to the management and occupational health personnel of the respective participating companies (Finnyards Ltd, Rauma, and Kemira Ltd, Harjavalta) and to the volunteer workers for their unfailing commitment to the study. Mr M Sunden (deceased) conducted the technical aspects of the industrial hygiene surveys at the workplaces. Ms A Lindell performed all of the aluminum analyses.

The study was financially supported by the Finnish Work Environment Fund.

\section{References}

1. Matczak W, Gromiec J. Evaluation of occupational exposure to toxic metals released in the process of aluminum welding. Appl Occup Environ Hyg. 2002;17:296-303.

2. Sjögren B, Lidums V, Håkansson M, Hedström L. Exposure and urinary excretion of aluminum during welding. Scand $\mathrm{J}$ Work Environ Health. 1985;11:39-43.

3. Sjögren B, Lundberg I, Lidums V. Aluminium in the blood and urine of industrially exposed workers. Br J Ind Med. 1983;40:301-4.

4. Sjögren B, Elinder C-G, Lidums V, Chang G. Uptake and urinary excretion of aluminium among welders. Int Arch Occup Environ Health. 1988;60:77-9. 
5. Rossbach B, Buchta M, Csanády GA, Filser JG, Hilla W, Windorfer K, et al. Biological monitoring of welders exposed to aluminium. Toxicol Lett. 2006;162:239-45.

6. Hull MJ, Abraham JL. Aluminum welding fume-induced pneumoconiosis. Hum Pathol. 2002;33:819-25.

7. Valkonen S, Aitio A. Analysis of aluminium in serum and urine for the biomonitoring of occupational exposure. Sci Total Environ. 1997;199:103-10.

8. Priest ND. The biological behavior and bioavailability of aluminium in man, with special reference to studies employing aluminium-26 as a tracer: review and study update. J Environ Monit. 2004;6:375-403.

9. International Commission on Radiological Protection (ICRP). Human respiratory tract model for radiological protection: a report of a task group of the ICRP. Oxford: Pergamon Press, 1994. Annals of the ICRP, Human Respiratory Tract Model for Radiological Protection volume 24, no 1-3. ICRP Publication 66.

10. Elinder CG, Ahrengart L, Lidums V, Pettersson E. Sjögren B. Evidence of aluminium accumulation in aluminum welders. $\mathrm{Br}$ J Ind Med. 1991;48:735-8.

11. Riihimäki V, Hänninen H, Akila R, Kovala T, Kuosma E, Paakkulainen $\mathrm{H}$, et al. Body burden of aluminum in relation to central nervous system function among metal inert-gas welders. Scand J Work Environ Health. 2000;26(2):118-30.

12. Milačič R. Speciation of aluminum in clinical aspects (health \& disease). In: Cornelis R, Crews H, Caruso J, Heumann KG, editors. Handbook of elemental speciation II: species in the environment, food, medicine \& occupational health. Chichester (UK): John Wiley \& Sons; 2005. p 27-39.
13. Bast-Pettersen R, Skaug V, Ellingsen D, Thomassen Y. Neurobehavioral performance in aluminum welders. Am J Ind Med. 2000;37:184-92.

14. Kiesswetter E, Schäper M, Buchta M, Schaller KH, Rossbach B, Scherhag $\mathrm{H}$, et al. Longitudinal study on potential neurotoxic effects of aluminium: I: assessment of exposure and neurobehavioural performance of $\mathrm{Al}$ welders in the train and truck construction industry over 4 years. Int Arch Occup Environ Health. 2007;81:41-67.

15. Ljunggren KG, Lidums V, Sjögren B. Blood and urine concentrations of aluminium among workers exposed to aluminum flake powders. Br J Ind Med. 1991;48:106-9.

16. Gitelman HJ, Alderman FR, Kurs-Lasky M, Rockette HE. Serum and urinary aluminium levels of workers in the aluminium industry. Ann Occup Hyg. 1995;39:181-91.

17. Letzel S, Schaller KH, Angerer J, Drexler H, Weber A, Schmid $\mathrm{K}$, et al. Biological monitoring of occupational aluminium powder exposure. Occup Hyg. 1996;3:271-80.

18. Kallio A, Kiilunen M, Kivistö H, Pekari K, Valkonen S. Results of biomonitoring analyses in Biomonitoring Laboratory, Helsinki, Finland in 1997. Toxicol Lett. 1999;108:249-57.

19. Deutsche Forschungsgemeinschaft. List of MAK and BAT values 2007: maximum concentrations and biological tolerance values at the workplace. Weinheim (Germany): Commission for the Investigation of Health Hazards of Chemical Compounds in the Work Area; 2007. Report no 43.

Received for publication: 28 February 2008 